\title{
O BRASIL NA PERSPECTIVA “DEL OTRO”: TWEETS JORNALÍSTICOS SOBRE A VOTAÇÃO PARA O IMPEACHMENT DE DILMA ROUSSEFF
}

\author{
André Firpo Beviláqua ${ }^{\mathrm{i}}$ \\ Helena dos Santos Kieling ${ }^{\text {ii }}$ \\ Alan Ricardo Costaii
}

\begin{abstract}
Resumo: Este estudo versa sobre os tweets jornalísticos, sumariamente definidos como enunciados produzidos e veiculados na rede social Twitter em contas de empresas jornalísticas. O objetivo principal da pesquisa é analisar, em um corpus definido a partir de um tema e de um período específico, como dois jornais argentinos, Clarín e La Nación, vêm construindo tais enunciados para tratar de uma questão tão cara à política brasileira: o processo de impeachment contra Dilma Rousseff. Apesar de o estudo apresentar gráficos e tabelas para substanciar e organizar os tweets jornalísticos, a discussão não se dá apenas em um viés quantitativo, pois os dados apresentados são discutidos qualitativamente. Os resultados indicam que os tweets jornalísticos hibridizam potencialidades técnicas do Twitter e características da linguagem jornalística. Além disso, a pesquisa avança ao mostrar como as imagens vêm constituindo importantes elementos para a construção do sentido sobre tais enunciados.
\end{abstract}

Palavras-chave: Twitter. Tweet jornalístico. Gênero jornalístico. Enunciado.

\begin{abstract}
This study addresses news tweets, defined as statements produced and broadcasted in Twitter social network, through news agencies' accounts. The main objective of this research is to analyze, in a corpus defined by a specific theme and period, how two Argentinean newspapers, Clarín and La Nación, have been building such statements to deal with a very sensitive issue in Brazilian politics: the impeachment proceedings against Dilma Rousseff. Although this study presents charts and tables in order to substantiate and organize the news tweets, the discussion is not only quantitative, since the data is also discussed qualitatively. Results indicate that news tweets hybridize Twitter's technical potentialities with the characteristics of the journalistic style. Moreover, the research shows how images have become important elements in making sense of such statements.
\end{abstract}

Keywords: Twitter. News tweet. Journalism genre. Statements.

\footnotetext{
i Mestrando em Letras pela Universidade Católica de Pelotas (UCPel). E-mail: andre.firpo@gmail.com. ii Mestranda em Letras pela Universidade Católica de Pelotas (UCPel). E-mail: kieling.helena@gmail.com. iii Mestre em Letras pela Universidade Católica de Pelotas (UCPel). E-mail: alan.dan.ricardo@gmail.com.
} 
EID\&A - Revista Eletrônica de Estudos Integrados em Discurso e Argumentação, Ilhéus, n. 12, jul/dez.2016.

\section{Introdução}

O Twitter ${ }^{1}$ é um dos websites mais populares no Brasil e no mundo, com 313 milhões de usuários ativos por mês, segundo informações da própria companhia ${ }^{2}$. De acordo com Recuero (2012), o Twitter funciona não apenas como site de rede social, por seus atores e conexões, mas também - enquanto rede - como meio de comunicação. Para o presente trabalho, contudo, cabe destacar que, por propiciar interação online entre usuários por meio de enunciados, o Twitter vem sendo uma importante ferramenta em diversos campos da atividade humana. Na Educação, por exemplo, Mattar (2013) apresenta inúmeras iniciativas envolvendo a plataforma, entre as quais destacamos a \#eadsunday, hashtag, utilizada por educadores de todo o mundo para debater sobre Educação a Distância (EaD) e temas afins.

Apesar do alcance e da importância do Twitter em diversas sociedades do globo, existem enunciados produzidos na plataforma que, conforme indica Teixeira (2015), ainda não foram suficientemente explorados. É o caso dos tweets jornalísticos, a que nos dedicaremos neste estudo, e que são enunciados elaborados e veiculados no Twitter por empresas jornalísticas e/ou profissionais da área (TEIXEIRA, 2015).

No presente artigo, pretendemos compreender como dois jornais argentinos - Clarín e La Nación - vêm construindo os tweets jornalísticos sobre um tema de grande repercussão no Brasil. Selecionamos um tópico específico e um período específico para, a partir disso, analisar como empresas jornalísticas têm elaborado e veiculado, no Twitter, os enunciados de um assunto tão caro a nós brasileiros: a articulação de um processo de impeachment presidencial sustentado por acusações questionáveis do ponto de vista legal. Mais detalhes sobre o corpus da pesquisa serão oferecidos em seções subsequentes.

Para as análises dos tweets jornalísticos, partiremos de considerações de Teixeira (2015), principalmente no que concerne à hibridização de propriedades da linguagem jornalística e de propriedades técnicas do Twitter. No entanto, além de discutir aspectos apresentados pela autora, tais como microlide, cartola, hashtags, links, arrobas, retweets, entre outros, pretendemos observar que esses tipos "relativamente estáveis de enunciados" (BAKHTIN, 2015, p. 262) vêm apresentando outras características.

\footnotetext{
${ }^{1}$ https://twitter.com/

${ }^{2}$ Notícia disponível em: <https://about.twitter.com/pt/company>. Acesso em: 9 set. 2016.
} 
EID\&A - Revista Eletrônica de Estudos Integrados em Discurso e Argumentação, Ilhéus, n. 12, jul/dez.2016.

Assim, iniciaremos o estudo tecendo algumas considerações sobre a perspectiva teórica considerada no trabalho. Em um segundo momento, explicaremos os procedimentos metodológicos adotados, tratando principalmente de questões relativas ao corpus e ao caminho percorrido nas análises. Posteriormente, apresentaremos os resultados alcançados neste estudo, assim como algumas discussões que percebemos como profícuas para a área. Ao final, formularemos algumas considerações finais e apresentaremos as referências bibliográficas consultadas.

\section{Algumas contribuições da Análise Dialógica do Discurso (ADD)}

A perspectiva teórica adotada no presente trabalho, conforme explica Brait (2006), não é uma teoria e/ou análise do discurso proposta formalmente por Bakhtin. No entanto, no ponto de vista da autora, com o qual concordamos neste trabalho, o conjunto de obras de Bakhtin e de outros participantes do chamado Círculo de Bakhtin motivou o nascimento de uma teoria e/ou análise dialógica do discurso.

A Análise Dialógica do Discurso (doravante ADD), de acordo com Brait (2006), não considera categorias dadas a priori para serem aplicadas mecanicamente a textos e discursos com o intuito de compreender as formas de produção de sentido. Segundo Sobral e Geletkanicz (2013, p. 221), a ADD, no lugar de categorias a priori que acabamos de mencionar, opta por instigar "modos específicos de perceber o objeto sem que as possibilidades de trabalho com ele se esgotem nas mesmas abordagens viabilizadas".

Nessa linha de argumentação, podemos pensar que Bakhtin, conforme discute Brait (2006), não desenvolve conceitos como o de polifonia, por exemplo, para posteriormente aplicá-los a determinadas obras. É na leitura e na análise detalhada da obra de Dostoiévski que o Círculo de Bakhtin configura o gênero como polifônico e, consequentemente, desenvolve o conceito de polifonia. Não custa reiterar, portanto, que o Círculo trata, inicialmente, de gêneros literários, mas com proposições conceituais que já de início, em considerável medida, se estendem a outras esferas de circulação dos discursos. Afinal, conforme apontado em Marxismo e filosofia da linguagem:

[...] cada época e cada grupo social têm seu repertório de formas de discurso na comunicação sócio-ideológica. A cada grupo de formas pertencentes ao mesmo gênero, isto é, a cada forma de discurso social, corresponde um grupo de temas [...] (BAKHTIN/VOLOSHINOV, 1999 [1929], p. 43). 
EID\&A - Revista Eletrônica de Estudos Integrados em Discurso e Argumentação, Ilhéus, n. 12, jul/dez.2016.

Nas últimas duas décadas, vários estudos (cf. RODRIGUES, 2008; SOBRAL e GELETKANICZ, 2013; SILVA, 2014) vêm considerando a ADD para analisar a construção de enunciados nos mais diversos "campos da atividade humana", os quais são considerados, nessa perspectiva, como "gêneros do discurso" (BAKHTIN, 2015, p. 262-263). O aumento significativo do número de pesquisas, no campo de estudos da Linguística Aplicada, em torno dos gêneros do discurso, alicerçadas pela ADD, se dá tanto pela consolidação da categoria gênero enquanto objeto de estudo quanto pela variedade de fenômenos sociais da linguagem que podem ser repensados e debatidos com base em tais perspectivas teóricas.

No estudo de Rodrigues (2008), a autora recorre aos princípios da ADD para analisar como se dá a construção discursiva da mulher e da beleza, assim como seus efeitos de sentido, em duas versões do conto "A pequena sereia", cujas ilustrações são de épocas diferentes. Em trabalhos como o de Sobral e Geletkanicz (2013), os autores apresentam uma maneira peculiar de descrever a arquitetônica de Luna Clara e Apolo Onze, texto verbal que integra recursos visuais. Em Silva (2014), a autora trata do ponto de vista crítico elaborado pelo publicitário e dono do perfil Dilma Bolada na rede social Facebook.

Tais investigações, apresentadas neste trabalho somente a título de ilustração, demonstram como a ADD pode auxiliar na análise de qualquer enunciado. Entre os variados enunciados, selecionamos, nas laudas a seguir, os chamados tweets jornalísticos, que, juntamente a outras mídias e sites de redes sociais, vêm causando significativas mudanças na forma de pensar e fazer o jornalismo online (ou webjornalismo). Para Teixeira (2015), os tweets jornalísticos, enquanto fenômeno social, no âmbito do ciberespaço, não apenas (re)formatam a forma do texto, mas também influenciam na própria relação do campo jornalístico com a notícia e com o "público-leitor".

\section{O caminho percorrido na realização do estudo}

Nesta seção, trataremos sobre os procedimentos metodológicos considerados no estudo, enfatizando principalmente questões relativas ao corpus e ao caminho percorrido nas análises.

O corpus da pesquisa foi selecionado em dois periódicos de grande circulação na Argentina, a saber: o jornal Clarín e o jornal La Nación. A partir de um tema específico - a votação para a instauração do processo de impeachment de Dilma Vana Rousseff na Câmara de Deputados, no Brasil - e de um período 
específico - entre os dias 16, 17 e 18 de abril, que correspondem, respectivamente, ao dia que antecedeu a votação, ao da votação e ao posterior à votação -, selecionamos os tweets jornalísticos para a análise.

Primeiramente organizamos a cobertura dos dois jornais nos três dias, avaliando a produção de tweets jornalísticos sobre o tópico no período considerado. Apesar de o estudo apresentar gráficos e tabelas para substanciar a análise e organizar os tweets, cabe ressaltar que não se trata de um trabalho quantitativo, tendo em vista que os dados serão comentados qualitativamente.

Finalmente, analisamos a hibridização de propriedades da linguagem jornalística e de propriedades técnicas do Twitter apresentadas por Teixeira (2015), mas sem limitar a análise aos aspectos discutidos pela autora. Em outras palavras, além de questões levantadas por Teixeira (2015) sobre tweets jornalísticos que empresas brasileiras vêm publicando na plataforma, verificamos que outras características têm sido observadas recorrentemente, de maneira mais ou menos estável.

\section{Discutindo os dados}

Iniciamos a ilustração dos dados coletados no estudo organizando os tweets jornalísticos na Figura 1 de acordo com o número de publicações em cada dia e em cada jornal. $O$ tema dos enunciados, cabe lembrar, é sempre o mesmo: a votação para a instauração do processo de pedido de abertura de impeachment da presidenta eleita em 2014, Dilma Rousseff, na Câmara de Deputados, no Brasil.

Figura 1 - Organização dos tweets jornalísticos

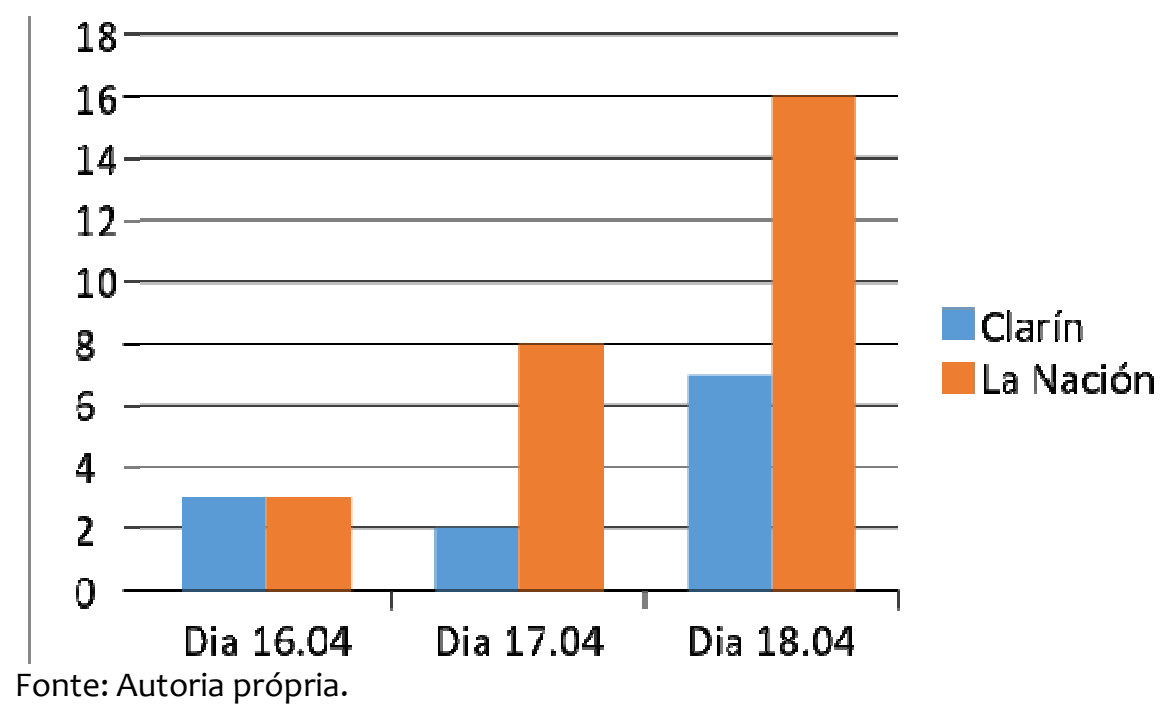


EID\&A - Revista Eletrônica de Estudos Integrados em Discurso e Argumentação, Ilhéus, n. 12, jul/dez.2016.

No primeiro dia da votação, conforme podemos observar na Figura 1, as contas do Twitter do Clarín e do La Nación tiveram o mesmo número de publicações sobre o assunto, apresentando um total de três publicações cada. No segundo dia, o jornal La Nación apresentou uma cobertura notoriamente maior, publicando oito tweets jornalísticos, enquanto o Clarín apenas dois. No terceiro dia, finalmente, o jornal La Nación deu um destaque maior ao tópico do que o Clarín: foram dezesseis tweets jornalísticos no La Nación e sete no Clarín.

Tais questões, conforme entendemos, revelam que, pelo menos no período analisado, houve maior interesse do La Nación pelo tema em questão. Se admitirmos que o Twitter tenha um caráter cumulativo, ou seja, que a produção de sentidos sobre o fato noticiado tende a ocorrer a partir da articulação de enunciados publicados em fluxo na plataforma (THOMPSON, 2007), o número de publicações sobre um determinado tema pode ser um aspecto relevante.

Com relação ao segundo aspecto analisado, isto é, a hibridização de propriedades da linguagem jornalística e de propriedades técnicas do Twitter, consideramos os aspectos discutidos por Teixeira (2015), mas ficamos atentos a outras características recorrentes nos enunciados. Alguns itens discutidos pela autora, conforme mencionamos em laudas anteriores, são a) microlide; b) cartola; c) hashtags; d) links; e) arrobas; f) retweets.

O Dicionário do Jornalismo ${ }^{3}$, conforme informações retiradas do próprio veículo, é um dicionário ou glossário elaborado com o objetivo de reunir termos utilizados com frequência no jornalismo. Segundo a obra, o termo lead (ou lide) designa uma parte introdutória da matéria que deve esclarecer noções importantes sobre o fato noticiado, entre as quais estão: O quê? Quem? Onde? Quando? Como? e Por quê?.

Para Teixeira (2015), alguns elementos presentes no lide vêm sendo privilegiados no Twitter, aspecto que, conforme acreditamos, provavelmente está relacionado ao limite de 140 caracteres oferecidos pela rede social para a elaboração dos enunciados. Assim, segundo a autora, há o aparecimento de um núcleo informativo que prioriza dados como O quê? Quem? Onde?, constituindo uma espécie de microlide. Na Figura 2, verificamos que os tweets jornalísticos analisados, conforme preconizou Teixeira (2015), seguiam a tendência de reduzir as seis questões consideradas para a elaboração do

${ }^{3}$ Disponível em: <http://dicionariodejornalismo.blogspot.com.br/>. Acesso em: 10 abr. 2016. 
EID\&A - Revista Eletrônica de Estudos Integrados em Discurso e Argumentação, llhéus, n. 12, jul/dez.2016.

microlide, porém as questões privilegiadas não eram necessariamente as mesmas que a autora verifica em seu estudo.

Figura 2 - Microlide no Clarín com elementos definidos em termos de SIM (x) ou NÃO (-).

\section{Clarín 0 quê? Quem? Quando? Onde? Como? Por quê?}

\begin{tabular}{|c|c|c|c|c|c|c|c|}
\hline \multirow[t]{3}{*}{16.04} & 1. & $x$ & $x$ & - & - & $x$ & - \\
\hline & 2. & $x$ & $x$ & - & - & $x$ & - \\
\hline & 3. & $x$ & $x$ & $x$ & - & - & - \\
\hline \multirow[t]{2}{*}{17.04} & 4. & $x$ & $x$ & - & $x$ & - & - \\
\hline & 5. & $x$ & $x$ & - & $x$ & - & - \\
\hline \multirow[t]{7}{*}{18.04} & 6. & $x$ & $x$ & - & $x$ & $x$ & - \\
\hline & 7. & $x$ & $x$ & - & - & $x$ & - \\
\hline & 8. & $x$ & $x$ & - & - & $x$ & - \\
\hline & 9. & $x$ & $x$ & - & - & $x$ & - \\
\hline & 10. & $x$ & $x$ & - & - & $x$ & - \\
\hline & 11. & $x$ & $x$ & - & $x$ & - & - \\
\hline & 12. & $x$ & $x$ & - & $x$ & - & - \\
\hline
\end{tabular}

Fonte: Autoria própria (com base na consulta realizada entre os dias 16 a 18 de abril de 2016).

Na Figura 2, podemos verificar que alguns elementos do lide são sistematicamente privilegiados no Clarín. Conforme podemos observar, 0 quê? e Quem? são apresentados em um maior número de tweets jornalísticos. Com relação aos demais elementos do microlide, verificamos que há uma espécie de alternância entre Quando? Onde? e Como? Quando um dos três elementos é oferecido ao leitor, os demais normalmente não aparecem. Finalmente, é importante notar que o Por quê? foi negligenciado em todos os enunciados, muito possivelmente por seu caráter de justificativa e explicação de um fenômeno, o que demandaria maior número de caracteres em comparação aos aspectos mais objetivos e pontuais, como Quem? e Quando? Também não é difícil perceber que a explicação da conjuntura retratada na notícia pode ser interpretada como facultativa, se em comparação com O quê? e Quando?, fundamentais para a notícia. O mesmo fenômeno ocorre no La Nación, conforme mostra a Figura 3. 
EID\&A - Revista Eletrônica de Estudos Integrados em Discurso e Argumentação, llhéus, n. 12, jul/dez.2016.

Figura 3 - Microlide no La Nación com elementos definidos em termos SIM (x) ou NÃO (-).

\begin{tabular}{|c|c|c|c|c|c|c|c|}
\hline & $\begin{array}{c}\text { La } \\
\text { Nación }\end{array}$ & O quê? & Quem? & Quando? & Onde? & Como? & Por quê? \\
\hline \multirow[t]{3}{*}{16.04} & 1. & $x$ & $x$ & - & $x$ & - & - \\
\hline & 2. & $x$ & - & - & $x$ & - & - \\
\hline & 3. & $x$ & $x$ & - & - & $x$ & - \\
\hline \multirow[t]{8}{*}{17.04} & 4. & $x$ & $x$ & - & - & $x$ & - \\
\hline & 5. & $x$ & $x$ & - & - & - & - \\
\hline & 6. & $x$ & - & - & - & - & - \\
\hline & 7. & $x$ & $x$ & - & - & $x$ & - \\
\hline & 8. & $x$ & $x$ & - & - & - & - \\
\hline & 9. & $x$ & $x$ & - & $x$ & - & - \\
\hline & 10. & $x$ & $x$ & - & - & $x$ & - \\
\hline & 11. & $x$ & $x$ & - & - & - & - \\
\hline \multirow[t]{16}{*}{18.04} & 12. & $x$ & $x$ & - & $x$ & - & - \\
\hline & 13. & $x$ & $x$ & - & - & - & - \\
\hline & 14. & $x$ & - & - & $x$ & $x$ & - \\
\hline & 15. & $x$ & $x$ & - & - & - & - \\
\hline & 16. & $x$ & $x$ & - & - & - & - \\
\hline & 17. & $x$ & $x$ & - & - & - & - \\
\hline & 18. & $x$ & $x$ & - & - & $x$ & - \\
\hline & 19. & $x$ & $x$ & - & - & - & - \\
\hline & 20. & $x$ & - & - & - & - & - \\
\hline & 21. & $x$ & - & $x$ & - & - & - \\
\hline & 22. & $x$ & $x$ & - & - & $x$ & - \\
\hline & 23. & $x$ & $x$ & $x$ & - & - & - \\
\hline & 24. & $x$ & - & - & - & - & - \\
\hline & 25. & $x$ & $x$ & - & - & $x$ & - \\
\hline & 26. & $x$ & $x$ & - & - & - & - \\
\hline & 27. & $\mathrm{X}$ & $x$ & - & - & - & - \\
\hline
\end{tabular}

Fonte: Autoria própria (com base na consulta realizada entre os dias 16 a18 de abril de 2016).

Cabe ressaltar, no entanto, que a análise do lide representou, em vários momentos, tomadas de decisão por parte de quem os avaliava. Embora entendamos que o tweet jornalístico não é composto somente pelos 140 caracteres, limite imposto ao usuário do Twitter que escreve na plataforma, mas também por outros elementos inerentes ao enunciado (imagens, links, opção de responder, curtir, retweetar, entre outras), consideramos para a 
EID\&A - Revista Eletrônica de Estudos Integrados em Discurso e Argumentação, Ilhéus, n. 12, jul/dez.2016.

análise do microlide somente as partes digitadas pelas empresas jornalísticas no espaço restrito. Para compreender melhor, vejamos a figura abaixo.

\section{Figura 4 - tweet jornalístico $n^{\circ} 17$ (La Nación)}

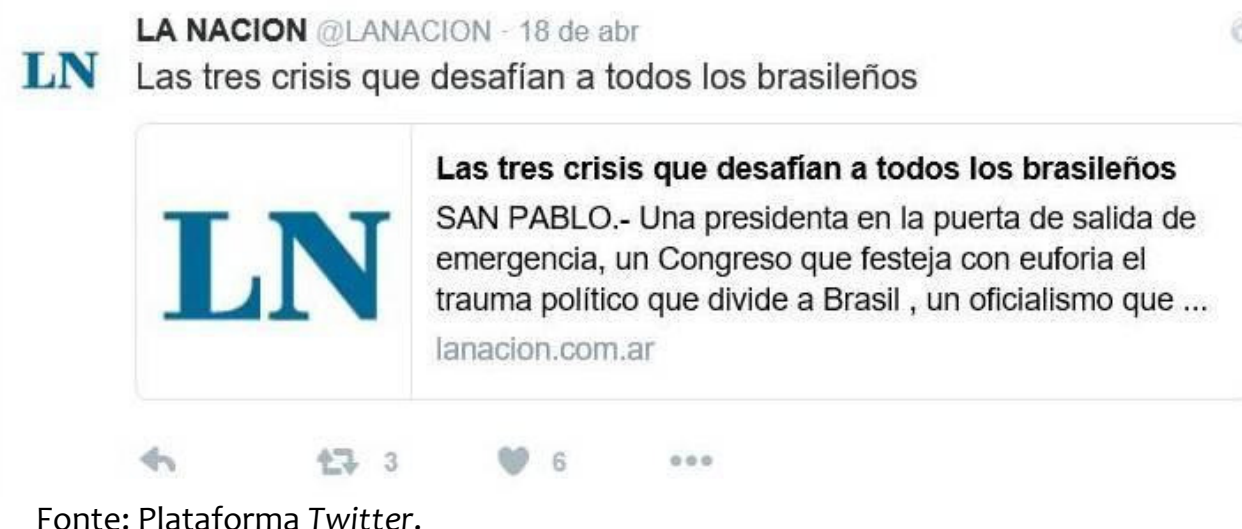

Fonte: Plataforma Twitter.

Conforme explica Teixeira (2015), o Twitter atualmente possibilita a inserção de links nos enunciados produzidos na plataforma, aspecto que podemos observar na Figura 4, em que um link é veiculado no tweet jornalístico. A inserção do link, segundo entendemos, é uma espécie de citação de outro enunciado jornalístico. a saber: uma notícia veiculada no site do La Nación. No entanto, embora o fragmento inserido por meio do link seja parte do enunciado e apresente informações importantes sobre o contexto imediato do fato noticiado, tais como Onde? ("SAN PABLO" e "Brasil"), não consideramos esses dados para a análise do microlide, pois não foram escritos nos 140 caracteres disponíveis para o usuário digitar.

Outro esclarecimento necessário sobre a análise do microlide diz respeito à informação Quando? Haja visto que o Twitter, como podemos visualizar na Figura 4, apresenta a data de publicação em qualquer enunciado elaborado na rede social, tal informação, no caso dos tweets jornalísticos, pode ou não coincidir com a época do acontecimento noticiado. No caso da Figura 4, por exemplo, a publicação é datada de 18 de abril, mesmo período das "três crises" noticiadas. Todavia, embora tenhamos consciência que a data de publicação é importante para a construção de sentidos sobre o enunciado em $\mathrm{si}$, não a consideramos como um elemento próprio do microlide, pois não é apresentada nos 140 caracteres disponíveis para o usuário digitar. 


\title{
Figura 5 - análise do lide no tweet n 23 (La Nación)
}

\author{
LN LA NAĆO puede pasar con Dilma tras la \\ votación de ayer bit.ly/1VwZMyw
}

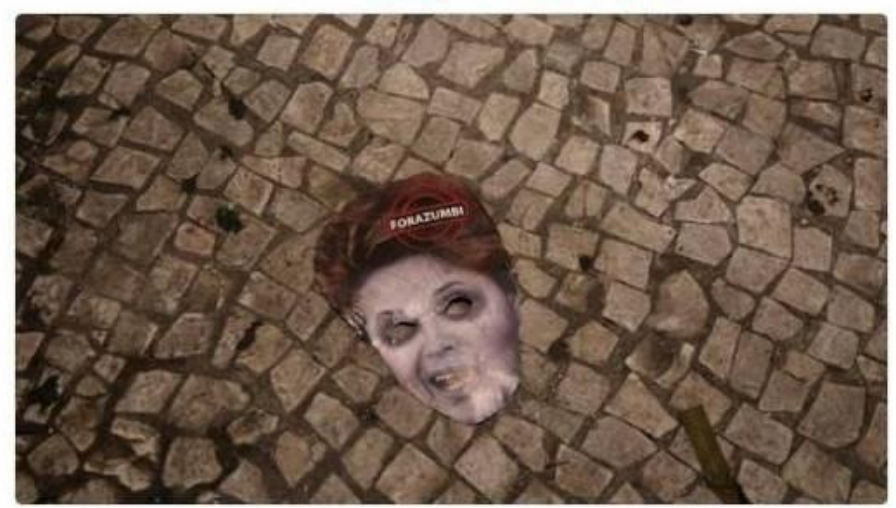

Fonte: Plataforma Twitter.

Na Figura 5, a articulação entre a data de publicação e o elemento do microlide Quando? pode contribuir significativamente para a construção do sentido sobre o fato noticiado, uma vez que a data de publicação é 18 de abril e o Quando? do microlide é "ayer”, que significa, em português, “ontem”. Destarte, para saber o significado do advérbio "ayer" precisamos saber a data de publicação do tweet jornalístico. O "ayer" do microlide, portanto, seria o dia que antecede a publicação do enunciado no Twitter: dia 17 de abril, data da votação para a implementação do processo de impeachment de Dilma Rousseff.

Nesse sentido, podemos observar que o enunciado em si - construído a partir da sinergia de diferentes semioses - e o período sócio-histórico no qual é produzido, envolvendo questões políticas, ideológicas, culturais, etc., atuam dialogicamente na construção do sentido, levando-nos a pensar no Quando? do microlide não somente em sua dimensão intralinguística, mas também em sua relação com o que é extralinguístico, como propõe a perspectiva bakhtiniana.

Outra propriedade da linguagem jornalística que os tweets jornalísticos vêm apresentando, conforme explica Teixeira (2015), é o uso da cartola, propriedade da linguagem jornalística definida pelo Dicionário do Jornalismo como uma ou mais palavras utilizadas sobre o título para definir o assunto da matéria. Para a autora, tal elemento pode apresentar três funções principais: 1) indicação temática: antecipa o tema noticiado, mas não possui caráter informativo e, 
portanto, não é fundamental para a sua compreensão; 2) termo contextualizador: possui um caráter mais informativo e, portanto, seu uso é mais necessário à construção do sentido; 3) indicador modal de link: funciona como indicador do material linkado, mostrando, inclusive, a sua natureza (áudio, vídeo, etc.).

No corpus selecionado para este estudo, conforme podemos observar na Figura 6 , verificamos somente uma vez a ocorrência da cartola no La Nación e nenhuma vez no Clarín.

Figura 6 - análise da cartola no tweet $n^{\circ} 22$ (La Nación)

LA NACION @LANACION - 18 de abr
LN [TITULOS] @Dilmabr, cerca del final: aprueban por amplio margen el
juicio político bit.ly/1TeweTa

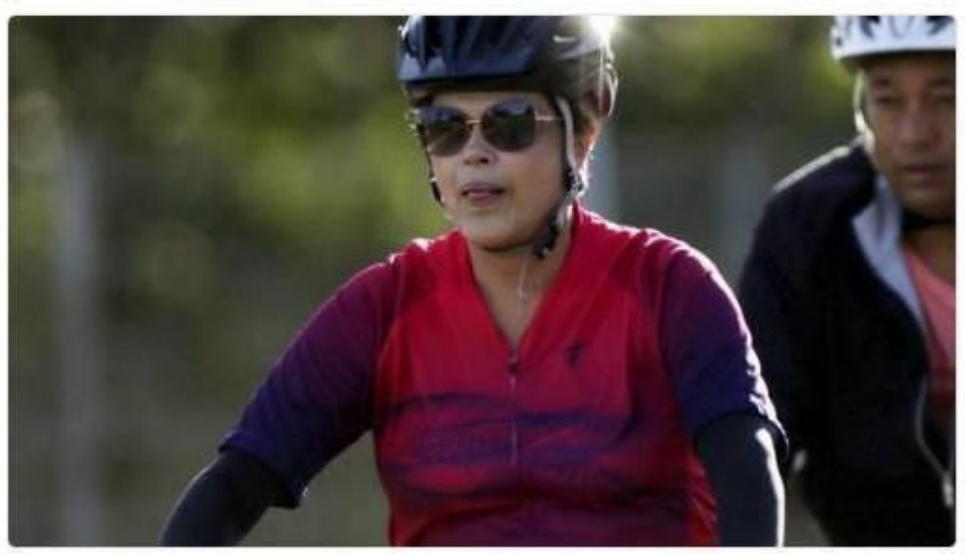

Fonte: Plataforma Twitter.

Na Figura 6, a cartola "[TíTULOS]" compõe o tweet jornalístico fazendo referência ao título de uma notícia veiculada por meio de um link que, da mesma forma que a cartola, constitui o enunciado. Desse modo, conforme entendemos, tal elemento funcionaria como o que Teixeira (2015) classifica como indicador modal de link.

Cabe ressaltar, no entanto, que, embora morfossintática e semanticamente o tweet jornalístico seja semelhante ao título da notícia, não podemos reduzi-lo a esse elemento composicional do gênero discursivo notícia, inclusive porque, conforme sabemos, embora o enunciado apresente uma espécie de citação de uma notícia, o contexto da enunciação nunca pode ser repetido. Além disso, os tweets jornalísticos possuem especificidades que impedem a sua classificação enquanto elementos constitutivos da notícia, 
EID\&A - Revista Eletrônica de Estudos Integrados em Discurso e Argumentação, Ilhéus, n. 12, jul/dez.2016.

como os títulos, aspecto evidenciado entre as marcas enunciativas, como o link, o nome do Twitter da presidenta Dilma Rousseff (@Dilmabr) e a cartola, elementos do enunciado da Figura 6 que não estão presentes na notícia do site do La Nación que foi veiculada pelo link.

Os tweets jornalísticos, conforme Teixeira (2015), também vêm apresentando características advindas do Twitter, entre as quais destacamos os links, arrobas, hashtags e retweets. No corpus analisado, identificamos que os links aparecem em todos os tweets jornalísticos do Clarín e do La Nación, aspecto que indica, até onde podemos perceber, que tais enunciados, embora apresentem as informações de maneira sucinta, apresentam duas possibilidades para a ampliação do conhecimento sobre um determinado assunto: 1) construção do sentido acompanhando os tweets jornalísticos publicados em fluxo; 2) leitura das notícias completas no site do jornal, veiculadas no enunciado por meio do link.

No que concerne ao uso de arrobas, verificamos o seu aparecimento somente duas vezes, ambas nos tweets jornalísticos do La Nación. A primeira delas, conforme vimos na Figura 6, foi para associar o nome Twitter da presidenta Dilma Rousseff no tweet jornalístico. A segunda delas, conforme veremos na Figura 7, aparece precedida da preposição "por" e aparentemente serve para indicar que o tweet jornalístico é um retweet da autora da notícia veiculada no enunciado por meio do link. Não encontramos, finalmente, nenhuma ocorrência de hashtags no corpus analisado.

Figura 7 - análise do uso de arroba no tweet n 12 (La Nación)

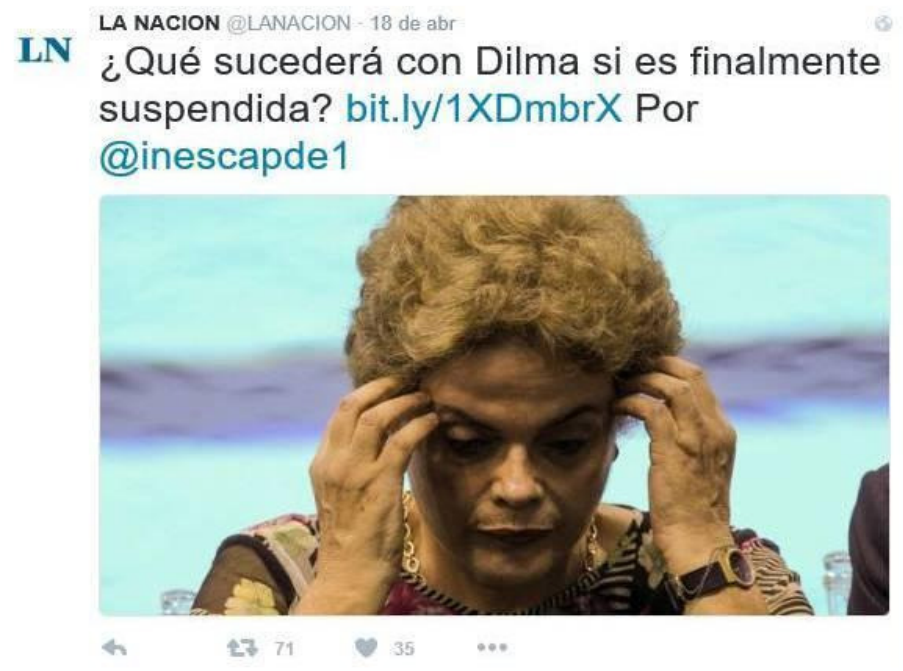

Fonte: Plataforma Twitter. 
EID\&A - Revista Eletrônica de Estudos Integrados em Discurso e Argumentação, Ilhéus, n. 12, jul/dez.2016.

Para Teixeira (2015), o retweet consiste em um mecanismo do Twitter para indicar que o conteúdo publicado provém de outro usuário. A autora discute três formas para retweetear um conteúdo. Resumidamente, o primeiro modo é utilizando o ícone retweetear, que importa o conteúdo de outro usuário sem possibilidade de edição, mantendo, inclusive, o seu "avatar". A segunda alternativa é por meio da fórmula “RT + @usuário + :", que também não permite edições no conteúdo retweeteado. A última possibilidade explanada pela autora é a inserção de "/via + @usuário"4 ou somente "via + usuário", que permite edições no conteúdo retweeteado.

$\mathrm{Na}$ Figura 7, o retweet aproxima-se bastante da terceira maneira de retweetear apontada por Teixeira (2015), com a diferença de que, no lugar de "via”, utiliza-se "por" para indicar a origem do conteúdo. As três estratégias, conforme sugere a autora, assemelham-se muito aos mecanismos de citação em discurso direto e indireto. Além disso, na nossa visão, são uma excelente estratégia para aproximar leitores do jornal com os jornalistas que produzem as notícias, propiciando não só que estes sejam seguidos no Twitter como também a interação entre ambos de maneira síncrona ou assíncrona.

Como explicamos no início do trabalho, além de discutir, com base em Teixeira (2015), sobre a hibridização entre propriedades da linguagem jornalística e de propriedades técnicas do Twitter nos tweets jornalísticos, pretendíamos analisar quais outras características tais enunciados têm apresentando recorrentemente, ainda que com certa flexibilidade. Entre elas, conforme discutiremos a seguir, as imagens vêm ganhando um papel de destaque.

As imagens, conforme entendemos, participam ativamente da construção do sentido sobre o fato noticiado, mostrando ser, consequentemente, um importante elemento na elaboração dos tweets jornalísticos. Sobre a articulação de signos ideológicos, reflete Bakhtin/Voloshinov (1999 [1929]):

Isso não significa, obviamente, que a palavra possa suplantar qualquer outro signo ideológico. Nenhum dos signos ideológicos específicos, fundamentais, é inteiramente substituível por palavras. É impossível, em última análise, exprimir em palavras, de modo adequado, uma composição musical ou uma representação pictórica. Um ritual religioso não pode ser inteiramente substituído por palavras. Nem sequer existe um substituto verbal realmente adequado para o mais simples gesto humano. Negar isso conduz ao racionalismo e ao simplismo mais grosseiros. Todavia, embora nenhum desses signos ideológicos seja substituível por palavras,

\footnotetext{
${ }^{4}$ O sinal de "+" foi inserido somente para indicar a superposição de elementos, não sendo, portanto, inserido nas "fórmulas" apresentadas para retweetear.
} 
EID\&A - Revista Eletrônica de Estudos Integrados em Discurso e Argumentação, Ilhéus, n. 12, jul/dez.2016.

cada um deles, ao mesmo tempo, se apóia nas palavras e é acompanhado por elas, exatamente como no caso do canto e de seu acompanhamento musical (BAKHTIN/VOLOSHINOV (1999 [1929], p. 25).

Tanto no Clarín como no La Nación, a maioria das imagens encontradas foram fotografias do banco de imagens de cada jornal, conforme o exemplo da Figura 8. No entanto, outros tipos de imagens encontradas em tais enunciados serão apresentados brevemente ao final do presente estudo.

Figura 8 - análise da imagem no tweet $n^{\circ} 1$ (Clarín).

Clarín.com@clarincom -16 de abr

Para la OEA, el juicio político contra Rousseff es ilegal clar.in/1Sdlt14

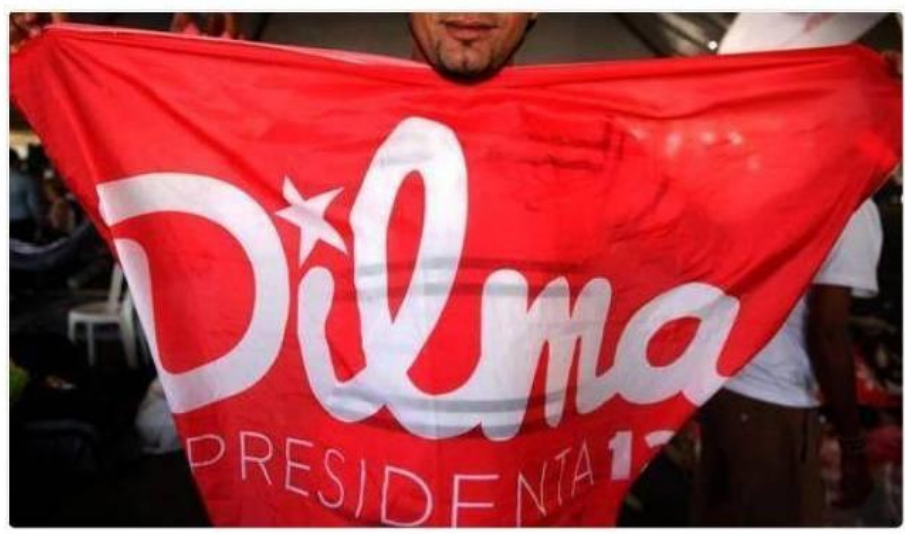

4 $47 \quad 37 \quad 020 \quad 00$

Fonte: Plataforma Twitter.

O tweet jornalístico da Figura 8, conforme podemos observar, apresenta o microlide e, logo abaixo dele, a fotografia de uma pessoa segurando a bandeira de Dilma Rousseff. Até onde podemos perceber, a sigla "OEA" do microlide diz respeito à "Organização dos Estados Americanos", organismo que possui, entre os seus objetivos, o de "promover e consolidar a democracia representativa, respeitando o princípio da não intervenção" 5 . Tal organismo, segundo a informação do microlide, considera o juízo político de "Rousseff" como sendo "ilegal".

Abaixo do microlide, há a fotografia de uma pessoa segurando uma bandeira vermelha, na qual está escrito "DILMA PRESIDENTA 13", na cor branca. Nesse sentido, o primeiro aspecto que chamou a atenção é que, até mesmo em detalhes como o nome da presidenta, o microlide e a fotografia

\footnotetext{
${ }^{5}$ Informações disponíveis em http://www.oas.org/pt/sobre/proposito.asp.
} 
EID\&A - Revista Eletrônica de Estudos Integrados em Discurso e Argumentação, Ilhéus, n. 12, jul/dez.2016.

parecem atuar de modo complementar na construção do sentido sobre o tweet jornalístico. Dito de outra forma, o nome "Dilma" apresentado na imagem é complementado pelo sobrenome "Rousseff" do microlide, formando o nome da presidente brasileira Dilma Rousseff.

No entanto, tal aspecto, evidentemente, pertence a um plano superficial da análise. Precisamos considerar, além dele, que a bandeira portada pela pessoa da fotografia foi distribuída nas últimas eleições presidenciais do Brasil, na qual Dilma Rousseff foi eleita democraticamente por milhões de brasileiros. Recentemente, a bandeira voltou a ser utilizada em manifestações contrárias ao impeachment da presidenta, de modo que o conteúdo apresentado no microlide e na imagem parecem estar em total consonância.

Assim, temos, de um lado, um microlide que apresenta a OEA como contrária ao impeachment, uma vez que considera o "juízo político" de Dilma Rousseff como "ilegal". De outro, temos a fotografia de uma pessoa segurando uma bandeira na qual está escrito "Dilma Presidenta 13", aspecto que revela, na nossa perspectiva, um posicionamento favorável à presidenta, ou seja, contrário ao impeachment. Nessa linha de argumentação, podemos dizer que o sentido no tweet jornalístico da Figura 8 é construído por meio da articulação de tais elementos, revelando, ainda que de maneira muito sutil, um posicionamento contrário ao impeachment, uma vez que tal ponto de vista não é apresentado como sendo o do jornal, mas o da pessoa que segura a bandeira (fotografia) e o da OEA do microlide. No entanto, conforme explica Bakhtin (1999), ainda que o discurso citado possa conservar certa autonomia semântica, o contexto que o integra nunca será o mesmo. Desse modo, o jornal, embora frequentemente faça referências ao discurso de terceiros em seus tweets jornalísticos, assume uma responsabilidade ao trazer aqueles dizeres aos enunciados que publica.

Finalmente, vale destacar que, além das fotografias, outros tipos de imagens foram apresentados nos tweets jornalísticos. Entre elas, além da ocorrência de fragmentos de notícias veiculadas por meio de links, conforme já havíamos mencionado na Figura 4, verificamos também imagens de capas das versões impressas dos próprios jornais e de outros. Além disso, os tweets jornalísticos atualmente oferecem opções como "curtir" e "responder", aspecto que, embora não tenhamos condições de tratar com mais profundidade neste trabalho, facilitam a interação entre jornal/jornalistas e leitores. 
EID\&A - Revista Eletrônica de Estudos Integrados em Discurso e Argumentação, Ilhéus, n. 12, jul/dez.2016.

\section{Considerações finais}

Neste estudo, tivemos a oportunidade de ampliar o diálogo sobre os tweets jornalísticos, definidos como enunciados produzidos por empresas jornalísticas e/ou profissionais da área no Twitter e tão importantes ao contexto do webjornalismo contemporâneo. Tais enunciados, conforme Teixeira (2015), vêm sendo elaborados por meio da hibridização de propriedades da linguagem jornalística e de propriedades técnicas do site de rede social Twitter.

Para as análises, além de aspectos discutidos por Teixeira (2015), consideramos outras características em tais enunciados, entre as quais destacamos as imagens e outras possibilidades como a de "curtir" e "responder". Em decorrência de sua importância para a construção do sentido, enfatizamos mais a primeira característica apresentada, mas não descartamos que a segunda amplia as possibilidades de interação entre jornal/jornalistas e leitores.

Finalmente, é importante salientar o papel do microlide dos jornais argentinos - Clarín e La Nación - na construção de enunciados para tratar de um episódio de impacto ímpar na política brasileira: a solicitação da abertura de um processo de impeachment, movido contra a presidenta Dilma Rousseff e efetivado até a data de conclusão deste artigo. Sem uma visão mais crítica e aguçada do microlide e sua relação com os demais elementos pertinentes ao gênero, a compreensão da notícia pode ser considerada notoriamente prejudicada.

\section{Referências}

BAKHTIN, Mikhail. Os gêneros do discurso. In: BAKHTIN, M. Estética da criação verbal. São Paulo: Martins Fontes, 2015. p. 261-306.

BAKHTIN, Mikhail; VOLOSHINOV, Valentin N. Marxismo e Filosofia da Linguagem. São Paulo: Hucitec, 1999 [1929].

BRAIT, Beth. Análise e Teoria do Discurso. In: . Bakhtin: outros conceitoschave. São Paulo: Contexto, 2006. p. 9-31. 
EID\&A - Revista Eletrônica de Estudos Integrados em Discurso e Argumentação, Ilhéus, n. 12, jul/dez.2016.

BRAVO. Dicionário de jornalismo. Disponível em: <https://www.blogger.com/profile/02001941607404926226>. Acesso em: 24 mai. 2016.

RECUERO, Raquel. A rede é a mensagem: efeitos da difusão de informações nos Sites de Rede Social. In: VIZER, E. (Org.). Lo que Mcluhan no previó. Buenos Aires: Editorial La Crujía, 2012, v. 1, p. 205-223. Disponível em: <http://www.raquelrecuero.com/arquivos/redemensagem.pdf>. Acesso em: 29 mai. 2016.

RODRIGUES, Rosangela Hammes. A análise do discurso na perspectiva do círculo de Bakhtin: uma análise dialógica do discurso. In: MOTA-ROTH, D.; CABAÑAS, T.; HENDGES, G. R. (Org.). Análise de textos e de discursos: relações entre teorias e práticas. Santa Maria: Editores, 2008. p. 65-87.

SILVA, Gilvaneide Pereira da. As vozes sociais no discurso dos memes Dilma bolada: uma perspectiva da análise dialógica do discurso (ADD) [trabalho de conclusão de curso]. Guarabira: Universidade Estadual da Paraíba, Curso de Letras, 2014.

SOBRAL, Adail; GELETKANICZ, Marice Fiuza. A arquitetônica de Luna Clara e Apolo Onze: uma reflexão metalinguística. Bakhtiniana: Revista de estudos do discurso, São Paulo, v. 8, n. 2, p. 220-240, jun. 2013.

TEIXEIRA, Mabel. Tipificação dos tweets jornalísticos. Sobre o Jornalismo, [em linha], v. 4, n. 2, p. 74-89, nov. 2015.

THOMPSON, Clive. Clive Thompson how Twitter creates a social sixth sense. Disponível em: <http://www.wired.com/2007/06/st-thompson-4/>. Acesso em: 01 abr. 2016.

Forma de citação sugerida:

BEVILÁQUA, André Firpo, KIELING, Helena dos Santos, COSTA, Alan Ricardo. O Brasil na perspectiva "Del Otro": tweets jornalísticos sobre a votação para o impeachment de Dilma Rousseff. EID\&A - Revista Eletrônica de Estudos Integrados em Discurso e Argumentação, llhéus, n. 12, p. 18-34, jul/dez.2016.

Recebido em: 12/10/2016

Aprovado em: 30/11/2016 